$\underline{\text { Avicenna Journal of Nursing and Midwifery Care - ISSN 2676-5748 }}$

\title{
Effect of Five A Model Self-management on Quality of Life in Patients with Breast Cancer
}

\author{
Marya Kalhor' ${ }^{1}$, Mohammad Fathi ${ }^{1}$, Bayazid Ghaderi', Daem Roshani ${ }^{1}$, Shadi Ozairi*1, Kourosh Rashidi ${ }^{1}$
}

1. Kurdistan University of Medical Sciences, Sanandaj, Iran

\begin{tabular}{lll}
\hline \multicolumn{1}{c}{ Article Info } & & ABSTRACT \\
\cline { 1 - 1 } $\begin{array}{l}\text { Received: } 2018 / 07 / 25 ; \\
\text { Accepted: } 2019 / 11 / 01 ;\end{array}$ & $\begin{array}{l}\text { Introduction: Applying group counseling and patient education can improve the } \\
\text { Published Online: } 2019 / 03 / 27\end{array}$ & $\begin{array}{l}\text { effect of applying a self-management model on the quality of life of patients with } \\
\text { breast cancer referring to Tohid Hospital in Sanandaj in } 2017 .\end{array}$
\end{tabular}

Methods: In this clinical trial, 90 patients with breast cancer were selected by available sampling method and randomly assigned to intervention $(n=45)$ and control $(n=45)$ group. Demographic and A QLQ-C30 questionnaires (quality of life for cancer patients) were used for data collection. After completing the questionnaires by both groups, for the patients in the experimental group, a five-year selfmanagement program was conducted in 5 stages for three months. For patients in the routine nursing care control group. Then, the questionnaires were completed by both groups three months after the intervention. Data were analyzed by SPSS 21 and descriptive statistics, pair t-test and independent t-test.

Results: There was a significant difference between the quality of life of the patients before and after the intervention. Also, there was a significant difference between the quality of life of the patients in the control group and the postintervention group $(P<0.05)$.

Conclusion: According to the results of this study, it seems that the application of the five A self-management model can improve the quality of life of cancer patients. Therefore, this model can be used as an optimal nursing intervention.

Keywords: Breast cancer; Self-management, Quality of life

\footnotetext{
Corresponding Information:

Shadi Ozairi, Kurdistan University of Medical Sciences, Sanandaj, Iran.

Email: shozairi97@gmail.com

Copyright $@$ 2019, This is an original open-access article distributed under the terms of the Creative Commons Attribution-noncommercial 4.0 International License which permits copy and redistribution of the material just in noncommercial usages with proper citation.
}

\section{How to Cite This Article:}

Kalhor M, Fathi M, Ghaderi B, Roshani D, Ozairi S, Rashidi K. Effect of Five A Model Selfmanagement on Quality of Life in Patients with Breast Cancer. Avicenna J Nurs Midwifery care. 2019; 27 (4): 269-280 


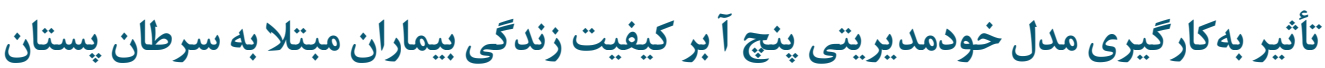 \\ ماريا كلهر'، حمد فتحى'، بايزيد قادرى'، دائم روشنى'، شادى عذيرى إ.، كوروش رشيدى' \\ | ا. دانشكاه علوميزشكى كردستان، سنندج، /يران}

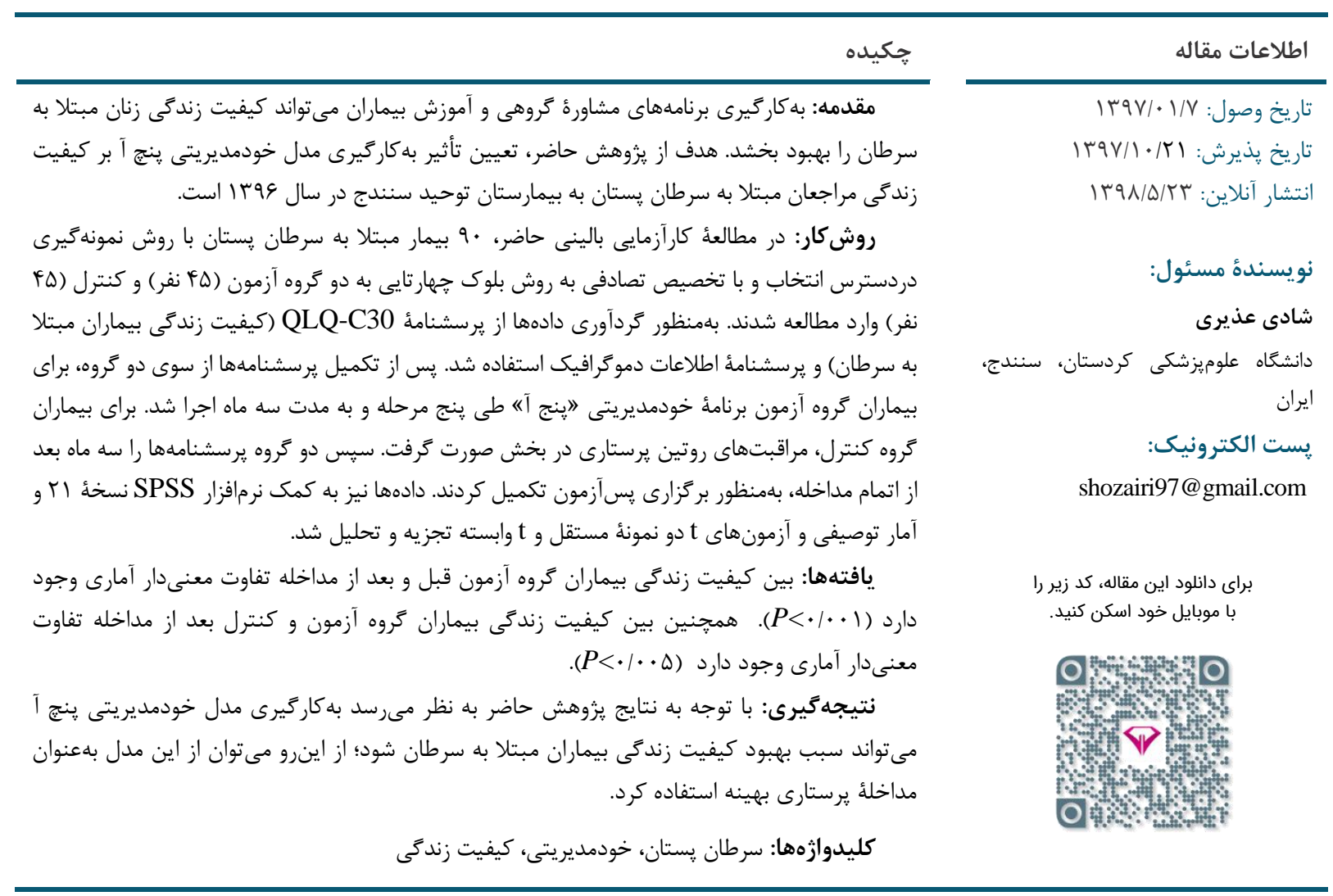

مقدمه

و نتيجه نمونهبردارى از بافت يستان بستگى دارد و شامل جراحى، راديوترايى، شيمىدرمانى، هورموندرمانى و درمان

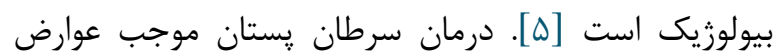

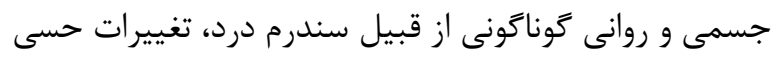
ناشى از برداشتن يستان، ادم لنفاوى، محدوديت حركت شانى شانه،

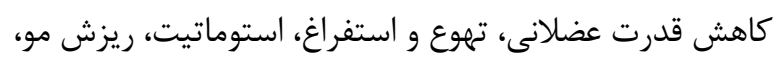
كاهش سلولهاى خونى، عفونت، اختلالات جنسى، اختلال در إنى

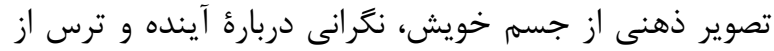

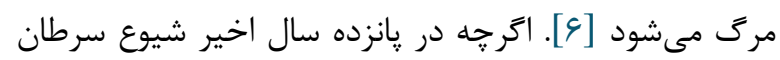

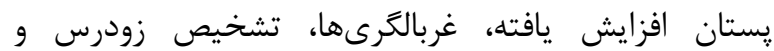
درمانهاى متعدد موجب كاهش مركَّمير در اين بيماران شده است. همجنين سرطان يستان به بيمارى مزمنى تبديل شده

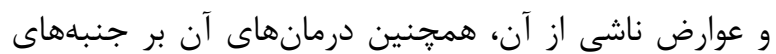

افزايش شيوع سرطان در سالهاى اخير و آثار آن بر جنبههاى

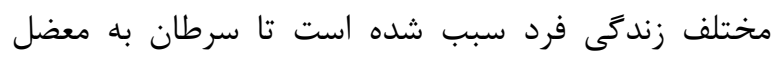

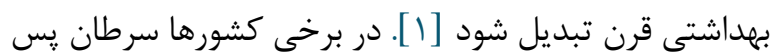
از بيمارى هاى قلبى - عروقى دومين عامل مركَومير به شمار مىرود، اما در ايران يس از بيمارىهاى قلبى - عروقى و سوانح،

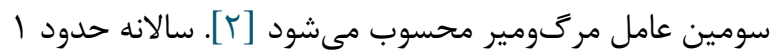

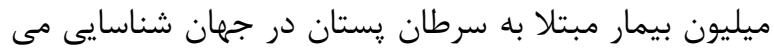

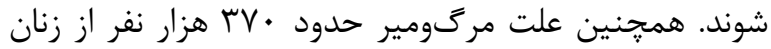

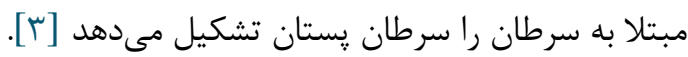
سرطان קستان تكثير بدخيم سلولهاى إيتليال است كه مجارى و لوبولهاى يك يا هر دو يستان را دركير مى كند [1 بـ.

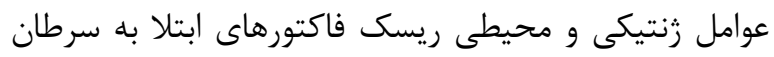

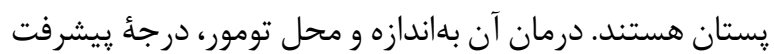




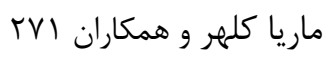

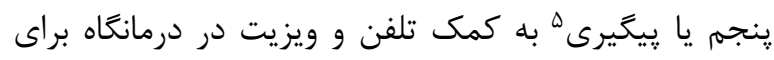

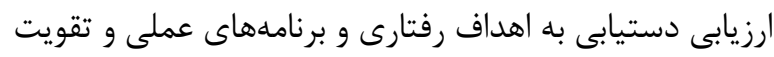

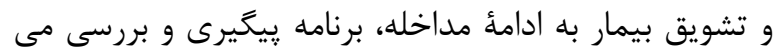

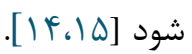
از آنجا كه يرستاران در بيمارستانها و كلينيكها با بيماران و خانواده آنان تماس دارند و به پِيشَيرى، شناسايى و كنترل

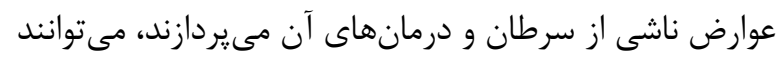

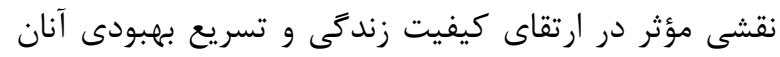

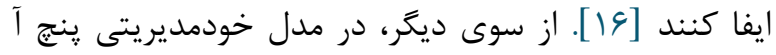

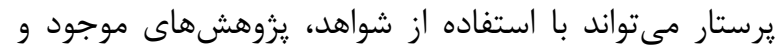

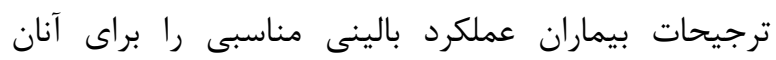

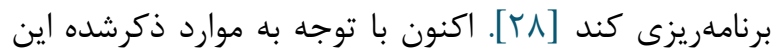

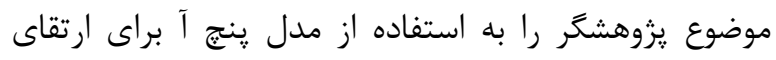

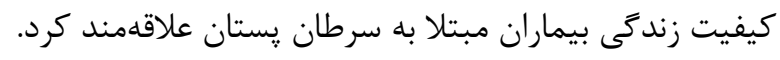

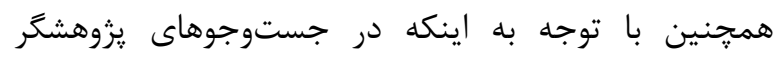

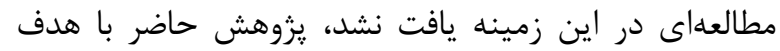

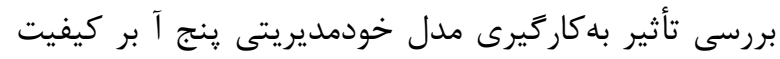

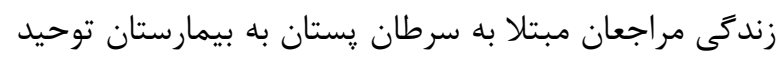
سنندج در سال \&9 با طراحى و اجرا شد.

\section{روش كار}

مطالعُ كارآزمايى بالينى حاضر از نوع تصادفى دو كروهى قبل

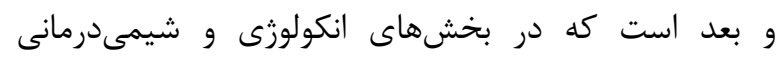
بيمارستان توحيد شهر سنندج در سال وه؟ با انجام شد. روش

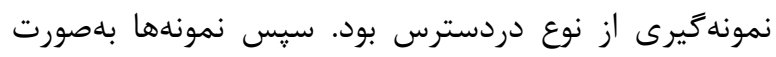

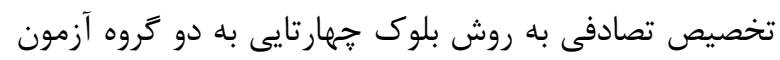
و كنترل تقسيم شدند. حجم نمونه در اين مطالعه •9 (ه أنفر

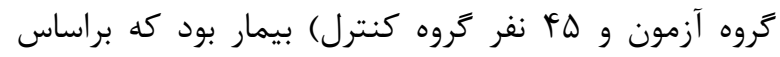

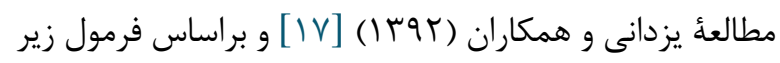

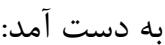

$$
n=\frac{\left(z_{1-\frac{\alpha}{2}}+Z_{1-\beta}\right)^{2}\left(\sigma_{1}^{2}+\sigma_{2}^{2}\right)}{\left(\mu_{1}-\mu_{2}\right)^{2}}
$$

معيارهاى ورود به مطالعه شامل زنان بالاى فّ سال، دريافت رضايت آكاهانه براى شركت در يزوهش، حداقل مداقل سواد خواندن

5. Assist

6. Arrange
كوناگون زندگى فرد تأثير گذار است و موجب كاهش كيفيت

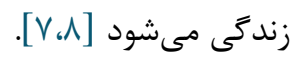
از سوى ديكر، كيفيت زندكى متأثر از وضعيت سلامت فيزيكى،

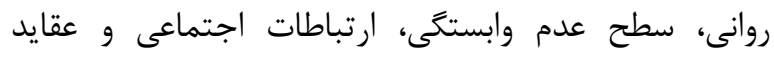
شخصى فرد است. ارائٔ تعريفى واضح و روشن براى ارتقاى إنى كيفيت زندكى كار دشوارى است، اما شايد بتوان كَفت ارتقاى

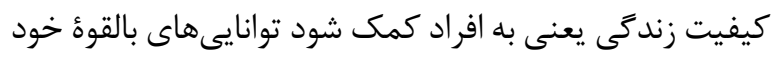

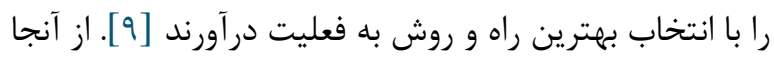
كه زنان از مهمترين اركان خانواده و جامعه هستند، ارتقاى

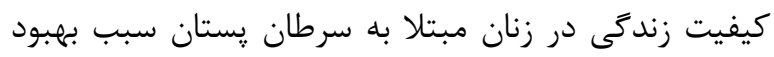

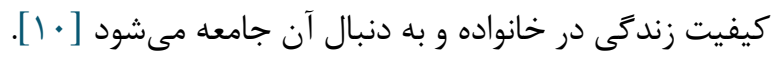

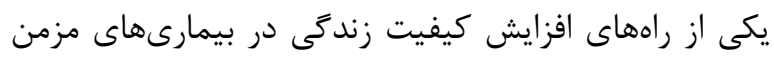

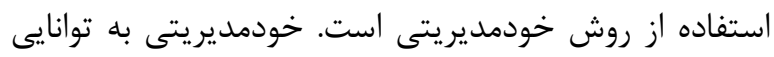

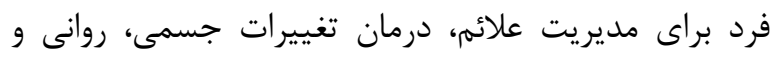

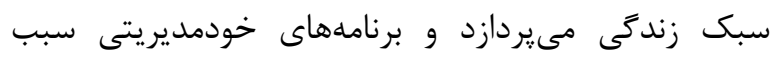
توانمندسازى افراد براى مقابله با بيمارىها و ارتقاى سطح

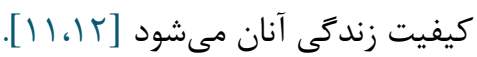

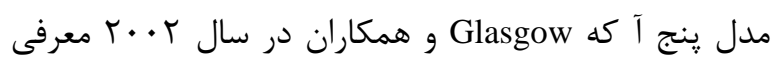
كردند، از جمله مدلها و برنامههاى خودمديريتى است كه به به مشاورة تغيير رفتار معروف است. همجنين رويكردى مبتنى بر

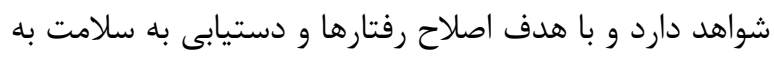

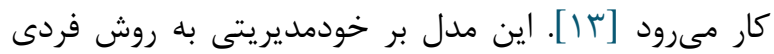

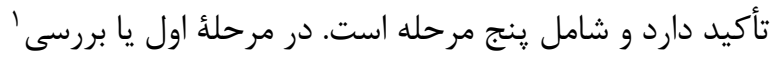

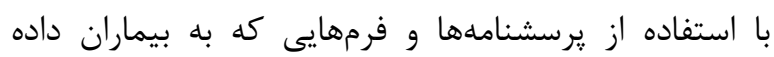

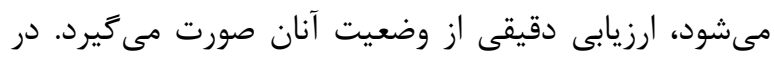

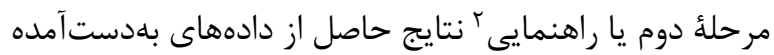

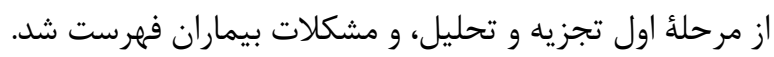

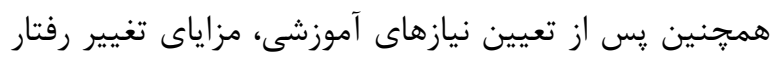

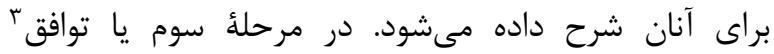

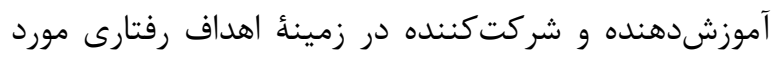

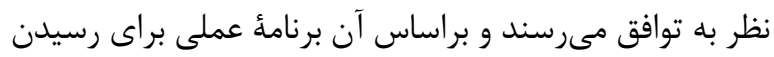

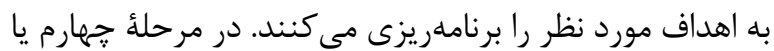

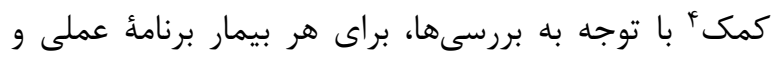

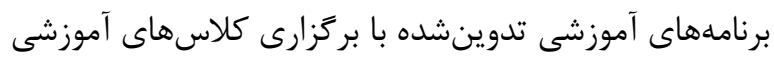

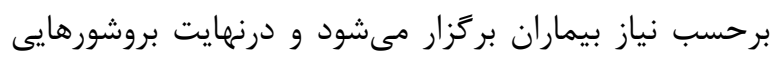

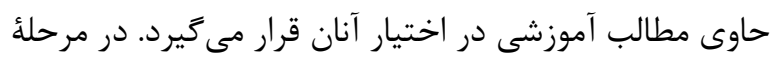

2. Asses

3. Advice

4. Agree 
اهداف مطالعه، همجِنين محر مانهماندن اطلاعات، جلب رضايت

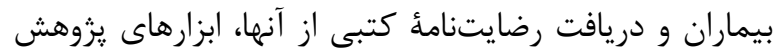

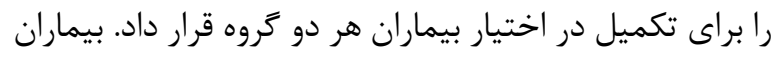

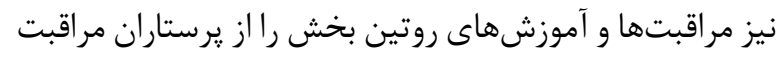
دريافت كردند. اين آموزشها شامل آموزشهاى شفاهى حين آنسين

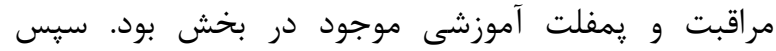

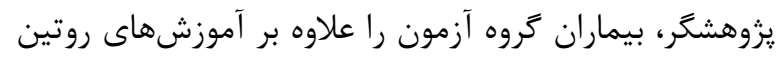

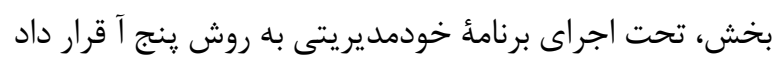

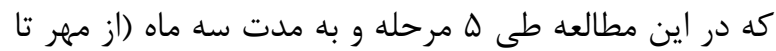
دىماه سال ع9ب () به شرح زير انجام شد:

كام اول (بر رسى) با استفاده از فرمهاى : يرسشنامه اطلاعات دموكرافيك و و يرسشنامهٔ اختصاصى كيفيت زندگى بررسى دقيقى از وضعيت

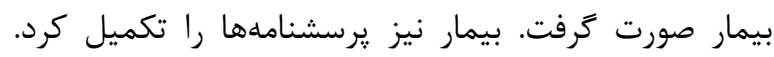

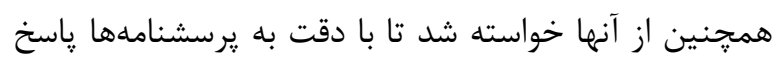

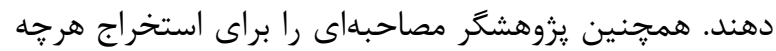
بيشتر مشكلات بيماران انجام داد.

كام دوم (راهنمايیى) براساس بررسى در كام اول، مشكلات هريك از بـ بيماران فهرست شد و خطرات انحراف سلامتى (براساس مشكلات

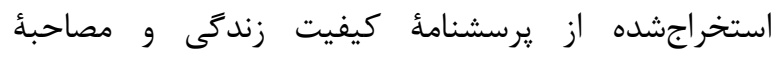

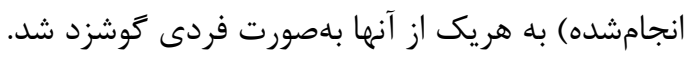

كام سوم (توافق) در اين مرحله، با تعيين و تنظيم واقعبينانه اهداف رفتارى متناسب با مشكلات تشخيص داده شده، با بيمار براى كاهش

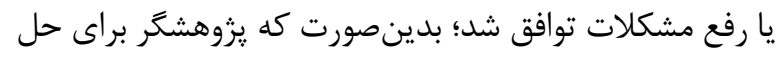

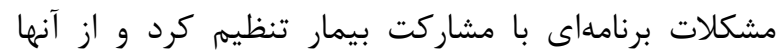

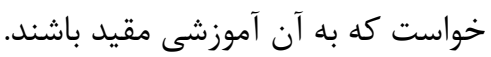

\section{كام جهارم (كمك)}

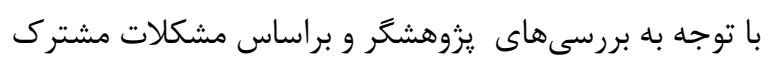

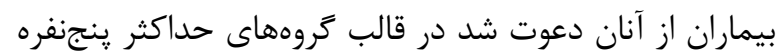
در دو جلسؤ آموزشى براى تحقق اهداف و رفع مشكلات شركت

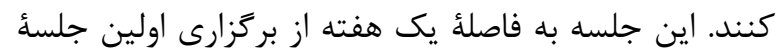
آموزش فردى بود. آموزش براساس مشكلات بيمار ان بان با استفاده از فيلمهاى آموزشى، اسلايد و سخنرانى صورت كرفت. جلسات آموزشى در كلاس تعيينشده در بيمارستان توحيد سنندج

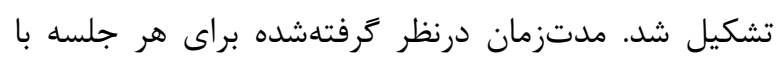

و نوشتن، تشخيص قطعى يزشك مبنى بر سرطان پِّتان و

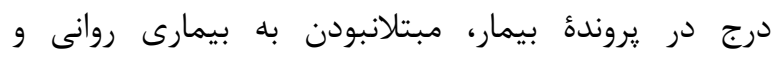

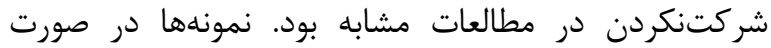

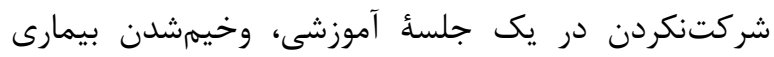
هنغام يزوهش و تمايلنداشتن به ادامهٔ همكارى از مطالعه

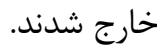

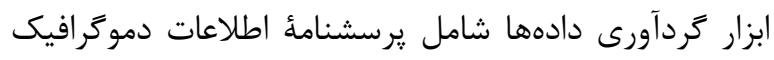

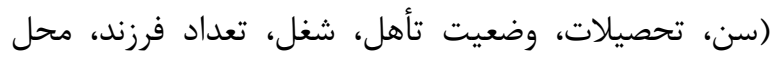
سكونت، مسئوليت و مسئوليت بيمارى) و يرسشنامهٔ كيفيت

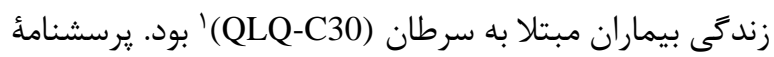

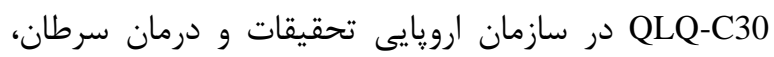
بهمنظور سنجش كيفيت زندكى بيماران مبتلا به سرطان در

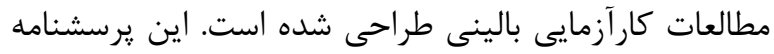

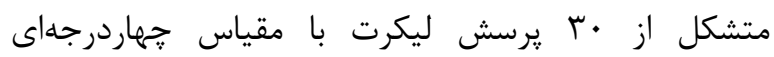

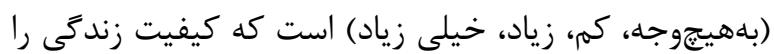
در ينج حيطؤ عملكردى (جسمانى، ايفاى نقش، احساسى،

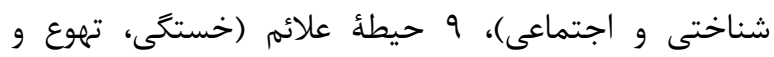

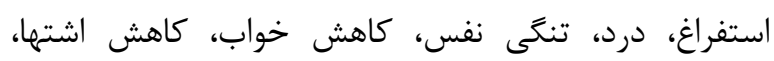
يبوست، اسهال و مشكلات مالى) و 1 حيطؤ كلى كيفيت زندگى اندازهگيرى مى كند. نمرهٔ هر حيطه در كسترهاى بين

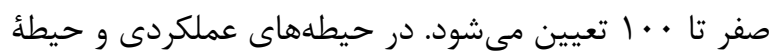

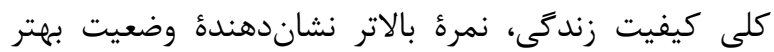
عملكرد يا كيفيت زندگى بهتر است؛ در حالى كه در حيطهُ علائم

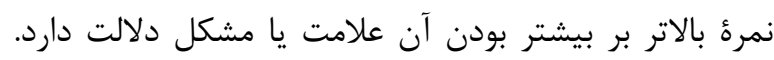

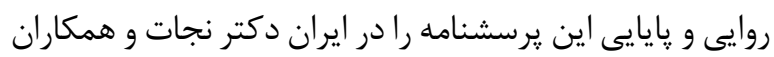
ارزيابى كردند. بر اين اساس، ضريب آلفا در تمام حيطهها

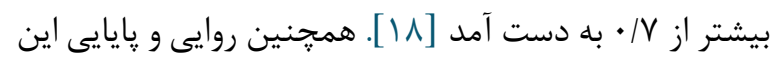
يرسشنامه در مطالعة Safaee و همكاران [19] ارزيابى شد كه إنه

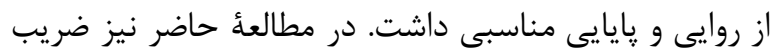

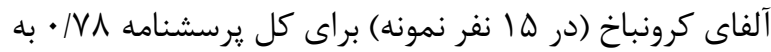

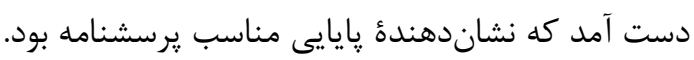

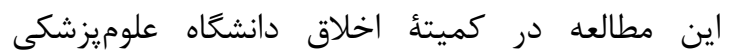
كردستان به شناسٔ IR.MUK.REC.1396/193 تأييد و با كد عد كار آزمايى بالينى IRCT201710159014N196 به ثبت رسيد. يروهشكر يس از دريافت مجوزهاى لازم و مراجعه به مراكز

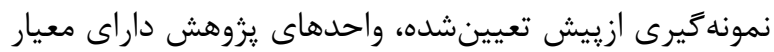

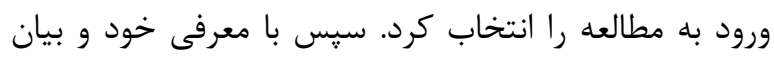

\footnotetext{
1. Quality of Life Questionnaire-Core 30(QLQ-C30)
}

$$
\text { مجله مراقبت يرستارى و مامايى ابنسينا }
$$




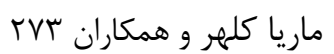

جدول ا. توزيع فراوانى متغيرهاى دموكرافيك و زمينهاى واحدهاى يزوهش در كروه آزمون و كنترل و مقايسئ آنها

\begin{tabular}{|c|c|c|c|c|c|c|c|}
\hline \multirow{2}{*}{$\begin{array}{l}P \\
\text { value }\end{array}$} & \multirow[t]{2}{*}{ آمارةً آزمون كاىدو } & \multicolumn{2}{|c|}{$\begin{array}{c}\text { كنترل } \\
N=45\end{array}$} & \multicolumn{2}{|c|}{$\begin{array}{l}\text { آزمون } \\
\mathrm{N}=45\end{array}$} & \multirow[t]{2}{*}{ سطوح متغير } & \multirow[t]{2}{*}{ متغير } \\
\hline & & درصد & تعداد & درصد & تعداد & & \\
\hline \multirow{3}{*}{$\cdot / \Lambda \Delta \Delta$} & \multirow{3}{*}{$\cdot|r|$} & $\Delta F / \Lambda$ & $r \Delta$ & 9.1. & Tr & زيردييلم & \multirow{3}{*}{ تحصيلات } \\
\hline & & $10 / 9$ & $v$ & $\mathrm{IV} / \mathrm{\Lambda}$ & $\wedge$ & دييله & \\
\hline & & $r V / r$ & Ir & $r T / r$ & 1. & دانشخاهى & \\
\hline \multirow{3}{*}{.$/ 8 \Delta V$} & \multirow{3}{*}{$\cdot / A r$} & $90 / q$ & rq & $g^{4} / \pi^{c}$ & rq & متأهل & \multirow{3}{*}{ وضعيت تأهل } \\
\hline & & $r \cdot / \Delta$ & 9 & $10 / 9$ & v & 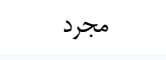 & \\
\hline & & $15 / 9$ & 9 & $r$. & 9 & بيوه و مطلقه & \\
\hline \multirow{4}{*}{. MEt } & \multirow{4}{*}{ D/F } & $11 / 4$ & Q & $s / V$ & r & بيكار و بازنشسته & \multirow{4}{*}{ وضعيت شغلى } \\
\hline & & $r \Delta / \Delta$ & $r \cdot$ & $\Delta V / \Lambda$ & re & خانهدار & \\
\hline & & $f \cdot / 9$ & 11 & $M F / F$ & 11 & 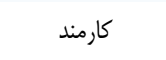 & \\
\hline & & $r / r$ & 1 & $11 / 1$ & $\Delta$ & آزاد & \\
\hline \multirow{2}{*}{.1090} & \multirow{2}{*}{ s/VT } & $m=/ l$ & 10 & $r V / \Lambda$ & IV & سنندج & \multirow{2}{*}{ محل سكونت } \\
\hline & & $9 \Delta / 9$ & $r$. & GT/T & ru & ساير شهرستانها & \\
\hline \multirow{2}{*}{ ג ג } & \multirow{2}{*}{.$/ 95$} & $N / r$ & $\wedge$ & $r \varepsilon / V$ & it & خير & \multirow{2}{*}{ سريرست خانواربودن } \\
\hline & & $\wedge) / \wedge$ & ge & $v / r$ & r & 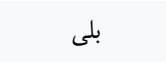 & \\
\hline \multirow[t]{2}{*}{.$/ 19 V$} & \multirow[t]{2}{*}{$1 / 91$} & $10 / 9$ & V & $g / V$ & r & خير & \multirow{2}{*}{ حمايت خانوادگى } \\
\hline & & $\Lambda F / 1$ & $r v$ & q & Ft & بلى & \\
\hline
\end{tabular}

مطالعه، جلسهاى آموزشى براى بيماران گروه كنترل بركزار و

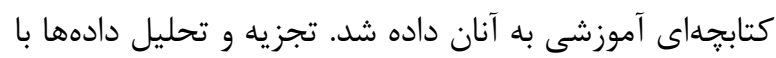

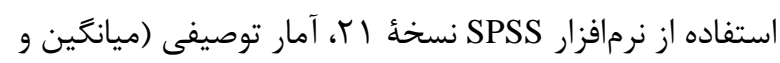

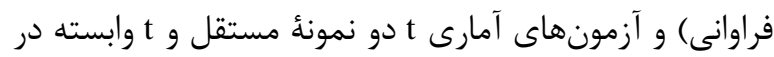

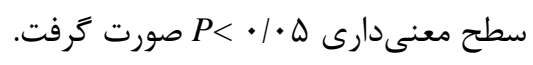

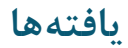

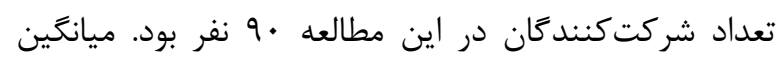

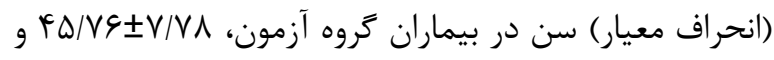

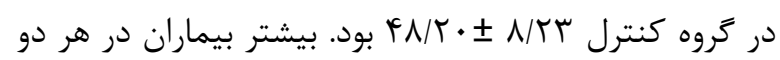

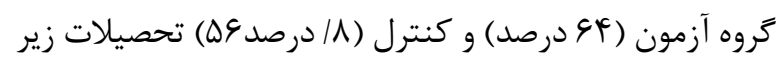

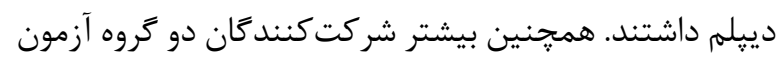

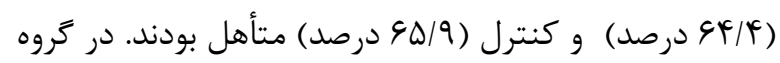

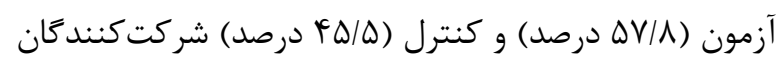

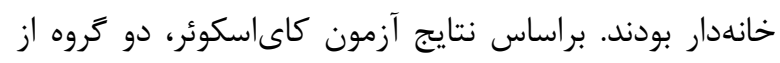
نظر مشخصات دموكرافيك (سن، تحصيلات، وضعيت تأهل، شغل، تعداد فرزند، محل سكونت، مسئوليت و مسئوليت
توجه به يزوهشهاى مشابه حداكثر إ/ ساعت بود. درنهايت

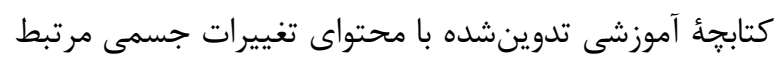

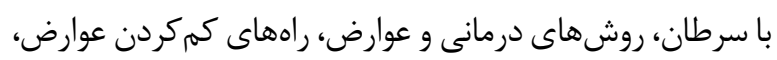

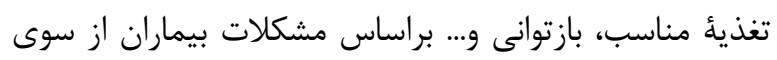
يزوهشكر با هدف استفاده در منزل در اختيار آنان قرار كرفت بران. دفتر جهاى نيز براى ثبت فعاليتهاى روزانه به آنها داده شد.

\section{كام ينجم (ييكيرى)}

عملكرد بيمار به مدت سه ماه بهمنظوي آنظور حصول اطمينان از

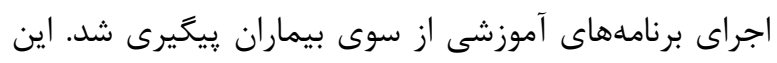

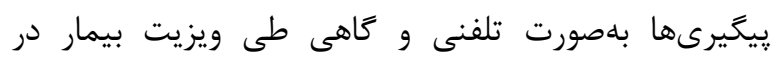

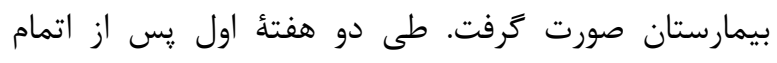

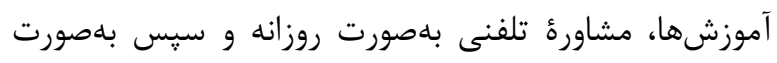
هفتتى براى يادآورى اجراى برنامئ آموزشى انجام شد.

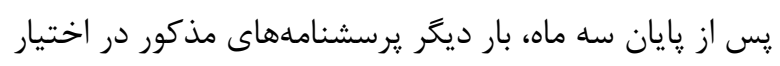

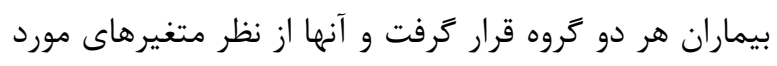

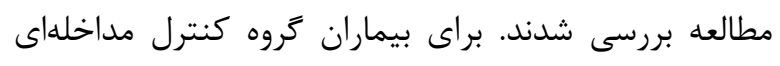
انجام نشد. همجنين بهمنظور رعايت مسائل اخلاقى در پإيان 
(جدول شمارة ؟)؛ بدينصورت كه در ابعاد

وضعيت كلى سلامت و ابعاد عملكردى (عملكرد جسمانى، ايفاى نقش، احساسى، شناختى و اجتماعى) بعد از مداخله،

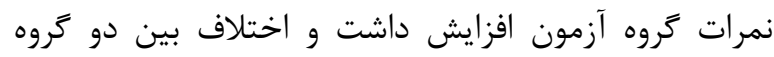

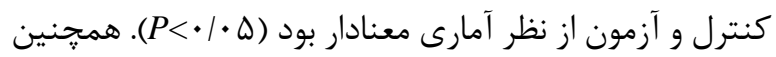

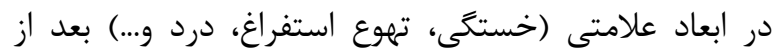

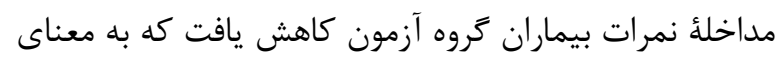

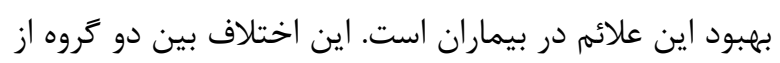

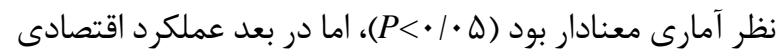
اختلاف نمرات بيماران دو گروه تفاوت معنادار آمارى نداشت

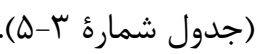

بيمارى) با هم تفاوت آمارى معنى دارى نداشتند و از اين نظر نمونهها همم

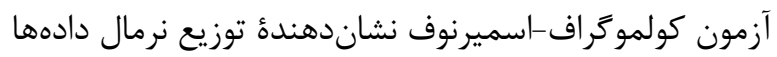

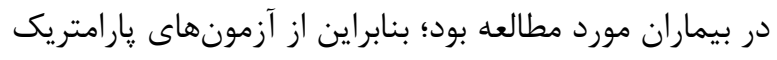

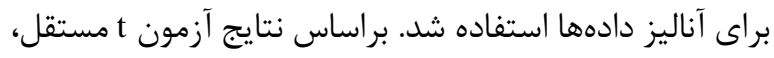

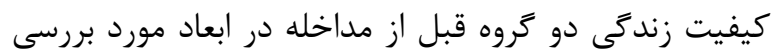

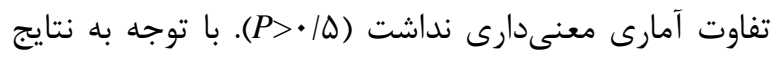

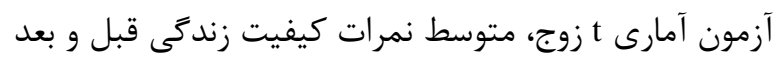

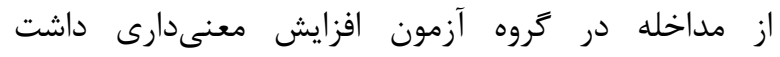

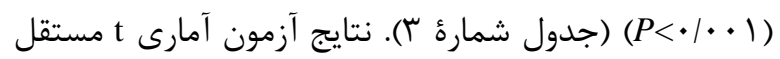

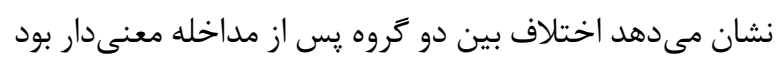

جدول r. توزيع فراوانى متغير هاى دموكر افيك كمى واحدهاى يخوهش در كروه آزمون و كنترل و مقايسة آنها

\begin{tabular}{|c|c|c|c|c|c|c|c|c|c|c|}
\hline & آمارة & & 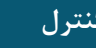 & & & & 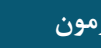 & 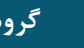 & & \\
\hline معنى & آزمت t & انحراف & ميانگين & حداكثر & حداقل & انحراف & ميانغين & حداكثر & حداقل & متغير \\
\hline - $/ \Delta T \Delta$ & $\cdot \mid 94$ & N/Tr & $Y \wedge / T$. & $9 V$ & rv & $V / V \Lambda$ & $f Q / V G$ & צ & ra & سن \\
\hline •/^९. & $-\cdot / 1 f$ & $r / T)$ & $r / V \cdot$ & 9 & · & I/AV & r/GY & V & · & تعداد فرزند \\
\hline$\cdot / 4 q$. & -.199 & $r \cdot / \& r$ & TN/FD & $1 \cdot 1$ & $\Delta$ & IV/AT & $T \Delta / \& V$ & 91 & r & مدتزمان بيمارى (ماه) \\
\hline$\cdot 1191$ & $-1 / 49$ & $9|\pi|$ & V/TL & re & $\cdot / \Delta$ & ו ו & $\Delta / \Lambda \Lambda$ & Ir & 1 & مدتز مان شيمى \\
\hline
\end{tabular}

جدول س. مقايسةُ نمرات حيطههاى كلى كيفيت زندكى در واحدهاى بثوهش قبل و بعد از آموزش در كروه آزمون و كنترل براساس

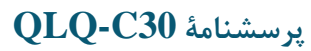

\begin{tabular}{|c|c|c|c|c|c|c|c|}
\hline \multirow[t]{2}{*}{$P$ value } & \multirow{2}{*}{ آزمون t } & \multicolumn{2}{|c|}{$\begin{array}{c}\text { كنترل } \\
N=44\end{array}$} & \multicolumn{2}{|c|}{$\begin{array}{l}\text { آزمون } \\
\mathrm{N}=45\end{array}$} & \multirow[t]{2}{*}{ زمان } & \multirow[t]{2}{*}{ متغير } \\
\hline & & انحراف معيار & ميانكين & انحراف معيار & ميانكين & & \\
\hline - & $\mathrm{t}=\cdot / 91$ & $\mid r / 4 F$ & एq/q & $18 / 4$. & $\Delta T / A T$ & قبل از مداخله & \\
\hline \multirow[t]{2}{*}{$<\cdot / . .1$} & $\mathrm{t}=s / \mathrm{v})$ & $\mid r / \cdot r$ & $\Delta V / \Delta F$ & $|r / 9|$ & $V \cdot|Q|$ & يّ از مداخله & كيفيت زندكَى \\
\hline & \multicolumn{3}{|c|}{$\begin{array}{l}\mathrm{t}=-r / r \varepsilon \\
P=\cdot 1 \cdots r\end{array}$} & \multicolumn{2}{|c|}{$\begin{array}{l}\mathrm{t}=-\mathrm{V} / \mathrm{Q} \varepsilon \\
P<\cdot / \cdots 1\end{array}$} & آمارة آزمون t زوجى & \\
\hline$\cdot 11 \cdot 1$ & $\mathrm{t}=1 / 9 \mathrm{r}$ & $19 / \pi T$ & ro/Ar & N/AT & $\Delta I / \wedge \Delta$ & قبل از مداخله & \\
\hline \multirow[t]{2}{*}{$<\cdot \mid \cdot .1$} & $\mathrm{t}=r / q \mathrm{~V}$ & $\mid Q / A V$ & $\mid c / 91$ & $19 / 99$ & $9 \cdot 109$ & يّ از مداخله & وضعيت كلى سلامتى \\
\hline & & \multicolumn{2}{|c|}{$\begin{array}{l}\mathrm{t}=-r / M \\
P=\cdot / . . r\end{array}$} & \multicolumn{2}{|c|}{$\begin{array}{l}\mathrm{t}=-\Delta / \leftarrow \wedge \\
P<\cdot / . .1\end{array}$} & آزمون t زوجى & \\
\hline
\end{tabular}


مVD

\begin{tabular}{|c|c|c|c|c|c|c|c|}
\hline \multirow[t]{2}{*}{$P$ value } & \multirow[t]{2}{*}{ آزمون t مستقل } & \multicolumn{2}{|c|}{$\begin{array}{c}\text { كتترل } \\
N=44\end{array}$} & \multicolumn{2}{|c|}{$\begin{array}{l}\text { آزمون } \\
N=45\end{array}$} & \multirow{2}{*}{ زمان } & \multirow{2}{*}{ متغير } \\
\hline & & انحراف معيار & ميانغَين & انحراف معيار & ميانگين & & \\
\hline$\cdot / F \Delta V$ & $\mathrm{t}=-\cdot / v \Delta$ & $19 / 49$ & $\Delta Q / 99$ & $10 / 9 \pi$ & $\Delta F / \wedge q$ & قبل از مداخله & \\
\hline \multirow[t]{2}{*}{.1 .49} & $\mathrm{t}=r / r \mu$ & $|N / V|$ & $91 / 41$ & $1 \% / \cdot 1$ & $99 / \cdot 4$ & سِ از مداخله & عملكرد جسمانى \\
\hline & & \multicolumn{2}{|c|}{$\begin{array}{l}\mathrm{t}=-1 / \Gamma \Delta \\
P=\cdot / / \Lambda \mathrm{F}\end{array}$} & \multicolumn{2}{|c|}{$\mathrm{t}=-\Delta / \bar{\varphi} \boldsymbol{t}$} & آمارة آزمون t زوجى & \\
\hline .1 .91 & $t=1 / \wedge 9$ & $r / / v q$ & gl/rg & 19/r & $99 / 9 \pi$ & قبل از مداخله & \\
\hline \multirow[t]{2}{*}{$<\cdot 1 . \cdot 1$} & $t=r / F r$ & $19 / \mathrm{vA}$ & gr/gr & $|g| g^{4}$ & $\Lambda \cdot / \mathrm{V}^{\mathrm{c}}$ & يس از مداخله & عملكرد ايفاى نقش \\
\hline & & \multicolumn{2}{|c|}{$\begin{array}{l}\mathrm{t}=-1 / \Delta T \\
P=. / / T \Delta\end{array}$} & \multicolumn{2}{|c|}{$P<\cdot 1 \cdot .1$} & آمارة آزمون t زوجى & \\
\hline$\cdot / N^{\pi} V$ & $\mathrm{t}=-\cdot / \mu \mathrm{r}$ & g & rT/QD & $r r / q 9$ & $r \cdot / 9 r$ & قبل از مداخله & \\
\hline \multirow[t]{2}{*}{.$/ . .1$} & $t=r / F i$ & $r r / \wedge q$ & MF/TA & to/gT & $\Delta) / \wedge \omega$ & مٍ از مداخله & عملكرد احساسى \\
\hline & & \multicolumn{2}{|c|}{$P=. / 19 \vee$} & \multicolumn{2}{|c|}{$P<\cdot / . \cdot 1$} & آمارة آزمون t زوجى & \\
\hline.$/ 11$ & $\mathrm{t}=1 / 8 \mathrm{r}$ & $r / 99$ & $\Delta \mathrm{V} / \Delta \mathrm{V}$ & $r \cdot / \pi \Delta$ & $99 / 9 \mathrm{~V}$ & قبل از مداخله & \\
\hline \multirow[t]{2}{*}{$<\cdot / . \cdot 1$} & $\mathrm{t}=\Delta / \wedge \mathcal{A}$ & $r M / I$ & $\Delta N / V I$ & $W / \& 9$ & & يَس از مداخله & عملكرد شناختى \\
\hline & & \multicolumn{2}{|c|}{$\begin{array}{c}\mathrm{t}=-1 \\
P=\cdot / \text { r Tr }\end{array}$} & \multicolumn{2}{|c|}{$P<\cdot \mid . .1$} & آمارة آزمون t زوجى & \\
\hline$\cdot \mid g^{\mu}$. & $\mathrm{t}=-\cdot / \kappa \wedge$ & rD/AT & $M / . \varphi$ & $r \cdot / v^{c}$ & $T N / 1 Q$ & قبل از مداخله & \\
\hline \multirow[t]{2}{*}{$\cdot / \cdot \cdot v$} & $t=r / v \Delta$ & rQ/VT & T Tוא & $T V / A T$ & $\mathrm{FV} / \cdot \mathrm{r}^{\mathrm{C}}$ & سِ از مداخله & عملكرد اجتماعى \\
\hline & & \multicolumn{2}{|c|}{$P=\cdot / \Delta \mathrm{V}$. } & $\mathrm{t}=-\Delta / \kappa$ & $P<\cdot \mid \cdot .1$ & آمارة آزمون t زوجى & \\
\hline
\end{tabular}

جدول ه. مقايسهُ نمرات حيطههاى علامتى كيفيت زندكى در واحدهاى بثوهش قبل و بعد از آموزش در عروه آزمون و كنترل براساس

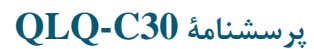

\begin{tabular}{|c|c|c|c|c|c|c|c|}
\hline \multirow[t]{2}{*}{$P$ value } & \multirow[t]{2}{*}{ آزمون t } & \multicolumn{2}{|c|}{$\begin{array}{l}\text { كنترل } \\
N=44\end{array}$} & \multicolumn{2}{|c|}{$\begin{array}{l}\text { آزمون } \\
\mathrm{N}=45\end{array}$} & \multirow{2}{*}{ زمان } & \multirow{2}{*}{ متغير } \\
\hline & & انحر اف معيار & ميانغين & انحراف معيار & ميانغين & & \\
\hline . & $t=-\cdot / 9 \Delta$ & $19 / V T$ & $\Delta 9 / \cdot 9$ & $r \cdot 1 \cdot q$ & $\Delta \Delta / \cdot \varphi$ & قبل از مداخله & \\
\hline \multirow[t]{3}{*}{$<\cdot / \cdot \bullet \mid$} & $t=-r / V q$ & $19 / 44$ & $\Delta F / \Delta F$ & $|0 / \pi|$ & re/vq & ֶِ از مداخله & علائم خستكى \\
\hline & & \multicolumn{2}{|c|}{$\mathrm{t}=r / 9 \mathrm{r}$} & \multicolumn{2}{|c|}{$t=\Delta / \wedge \Delta$} & t t آمارئ آزمون & \\
\hline & & \multicolumn{2}{|c|}{$P=\cdot / \cdot \bullet \Delta$} & \multicolumn{2}{|c|}{$P<\cdot / \cdot \cdot 1$} & زوجى & \\
\hline - ITAT & $t=-1 / 1 \Delta$ & $r T / T$. & $\Delta N / \Gamma r$ & $T F|q|$ & $\Delta r / \Delta q$ & قبل از مداخله & \\
\hline \multirow[t]{3}{*}{$<\cdot \mid \cdot \cdot 1$} & $t=-9|1|$ & $19 / 4 \Delta$ & $\Delta r / \cdot r$ & Tr/QT & $r া / \Lambda \Delta$ & پِ از مداخله & علائم تهوع و \\
\hline & & \multicolumn{2}{|c|}{$\mathrm{t}=r / \uparrow \varphi$} & \multicolumn{2}{|c|}{$\mathrm{t}=\mathrm{V} / / \Delta$} & t t آمارئ آزمون & \\
\hline & & \multicolumn{2}{|c|}{$P=\cdot / \cdot 1 \wedge$} & \multicolumn{2}{|c|}{$P<\cdot \mid \cdot \cdot 1$} & زوجى & \\
\hline $.11 \cdots$ & $\mathrm{t}=-1 / 99$ & ID/AT & $\Delta V / T$. & $1 N / 09$ & $\Delta 1 / 11$ & قبل از مداخله & درد \\
\hline
\end{tabular}


TVG بهكاركيرى مدل خودمديريتى ينج آ بر كيفيت زندكى...

\begin{tabular}{|c|c|c|c|c|c|c|c|}
\hline \multirow[t]{2}{*}{$P$ value } & \multirow[t]{2}{*}{ آزمون t } & \multicolumn{2}{|c|}{$\begin{array}{l}\text { كنترل } \\
N=44\end{array}$} & \multicolumn{2}{|c|}{$\begin{array}{l}\text { آزمون } \\
\text { N=45 }\end{array}$} & \multirow{2}{*}{ زمان } & \multirow{2}{*}{ متغير } \\
\hline & & انحر اف معيار & ميانغين & انحراف معيار & ميانغين & & \\
\hline \multirow[t]{3}{*}{$<\cdot / \cdot \cdot \cdot 1$} & $t=-V / \backslash \Lambda$ & $|8 / \pi|$ & $\Delta F / Q T$ & $\mid Q / F V$ & $r \cdot / V{ }^{F}$ & يس از مداخله & \\
\hline & & \multicolumn{2}{|c|}{$t=I / V V$} & \multicolumn{2}{|c|}{$\mathrm{t}=\Lambda /\left.\right|^{4}$} & t آمارئ آزمون t & \\
\hline & & \multicolumn{2}{|c|}{$P=\cdot 1 \cdot \wedge r$} & \multicolumn{2}{|c|}{$P<\cdot \mid \cdot \cdot 1$} & زوجى & \\
\hline$\cdot / F \cdot r$ & $\mathrm{t}=-\cdot / \lambda \mathrm{t}$ & $T \Delta / T K$ & \$9/94 & TVIAN & FT/TT & قبل از مداخله & \\
\hline \multirow[t]{3}{*}{$<\cdot \mid \cdot \cdot 1$} & $t=-r / v$. & $r \Delta / / T$ & $|q| \pi \mid$ & Tr/Vq & $r V / F I$ & يس از مداخله & علائم تنكى نفس \\
\hline & & \multicolumn{2}{|c|}{$\mathrm{t}=1 / \cdot \cdot$} & \multicolumn{2}{|c|}{$\mathrm{t}=r / \mu r$} & 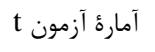 & \\
\hline & & \multicolumn{2}{|c|}{$P=\cdot / r Y T$} & \multicolumn{2}{|c|}{$P=\cdot \mid \cdot \cdot 1$} & زوجى & \\
\hline$\cdot / 11 \cdot$ & $\mathrm{t}=-1 / 91$ & $r \cdot|9|$ & QN/Tr & rN/9) & $\forall N / 1 \Delta$ & قبل از مداخله & \\
\hline \multirow[t]{3}{*}{$<\cdot / \cdot \cdot 1$} & $t=-r / \varepsilon \Lambda$ & $r \cdot / r 1$ & $\Delta 9 / .9$ & $T Y / T$. & rN/Aq & يس از مداخله & علائم بى خوابى \\
\hline & & \multicolumn{2}{|c|}{$t=1 / v V$} & \multicolumn{2}{|c|}{$\mathrm{t}=\mathrm{r} / \boldsymbol{F} \wedge$} & t آمارة آزمون t & \\
\hline & & \multicolumn{2}{|c|}{$P=\cdot 1 \cdot \wedge r$} & \multicolumn{2}{|c|}{$P<\cdot / \cdot .1$} & زوجى & \\
\hline$\cdot / r \vee q$ & $t=\cdot / \wedge 9$ & re/VV & $\Delta 9 / \cdot 9$ & $T T / T V$ & $s \mu / V$. & قبل از مداخله & \\
\hline \multirow[t]{3}{*}{$\cdot \mid \cdot \cdot 1$} & $t=-r / r r$ & $T F / A G$ & $\Delta 9 / \Lambda F$ & Tr/lg & FT/QG & يِ از مداخله & علائم كاهش اشتها \\
\hline & & \multicolumn{2}{|c|}{$t=-\cdot / \kappa q$} & \multicolumn{2}{|c|}{$\mathrm{t}=9 / \wedge$. } & t آمارئ آزمون t & \\
\hline & & \multicolumn{2}{|c|}{$P=\cdot \mid 94}$. & \multicolumn{2}{|c|}{$P<\cdot \mid \cdot \cdot 1$} & زوجى & \\
\hline$\cdot \mid q \vee \Delta$ & $\mathrm{t}=\cdot / \mathrm{rr}$ & $r y / q 1$ & T\&/QT & rF/aV & rq/9 & قبل از مداخله & \\
\hline \multirow[t]{3}{*}{$\cdot / \cdot \Delta V$} & $t=-1 / 94$ & MI/बr & $T F / T F$ & $r \cdot 109$ & r & پِ از مداخله & علائم يبوست \\
\hline & & \multicolumn{2}{|c|}{$\mathrm{t}=\cdot / \Delta \mathrm{T}$} & \multicolumn{2}{|c|}{$t=r / \wedge 9$} & t آمارئ آزمون t & \\
\hline & & \multicolumn{2}{|c|}{$P=\cdot \mid \varphi \cdot V$} & \multicolumn{2}{|c|}{$P<\cdot / \cdot \cdot 1$} & زوجى & \\
\hline$\cdot / 494$ & $t=-\cdot / V r$ & TY/FT & $r N / \cdot r$ & $r \cdot / \Lambda r$ & Tr/94 & قبل از مداخله & \\
\hline$\cdot / \cdot r$ & $t=-r / \cdot 9$ & $r \cdot \pi \Delta$ & $r \cdot \pi \cdot$ & $r \cdot 109$ & r & يس از مداخله & علائم اسهال \\
\hline & & & & & & آمارة آزمون t & \\
\hline & & & & & & زوجى & \\
\hline$\cdot / V V r$ & $\mathrm{t}=-\cdot / T \Lambda$ & TV/QT & VA/VA & $r q / 1 \Delta$ & $V V / \cdot r$ & قبل از مداخله & \\
\hline$\cdot / \cdot \Delta T$ & $t=-1 / 9 \mathrm{~V}$ & $T V / T$. & $\Lambda \cdot / r$. & $r \cdot / 9 r$ & $9 N / 10$ & ֶِ از مداخله & مشكلات مالى \\
\hline & & & & & & آمارة آزمون t & \\
\hline & & & & & & زوجى & \\
\hline
\end{tabular}

يستان تأثير گذار بود؛ بهطورى كه كيفيت زندگى يس از

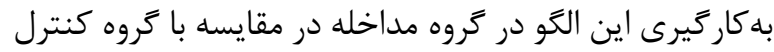

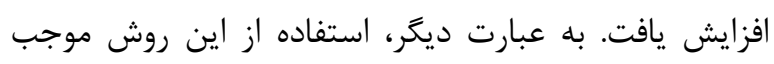

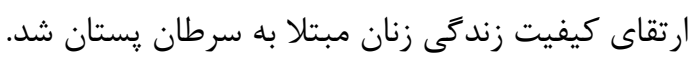

يزوهش حاضر با هدف بررسى تأثير بهكارگيرى مدل

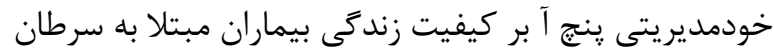

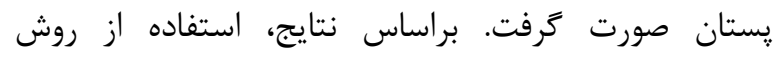
خودمديريتى ينج آ بر كيفيت زندگى زنان مبتلا به سرطان 
در بعد عملكرد احساسى، ميانگين نمرات در كروه آزمون

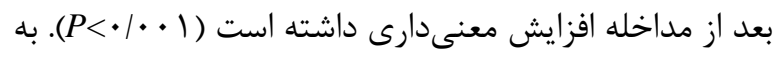
نظر مىرسد كذشت زمان، مداخلة آموزشى و مكانيسمهاى

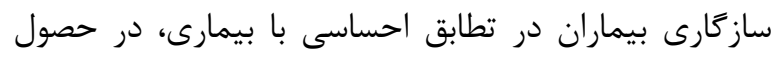

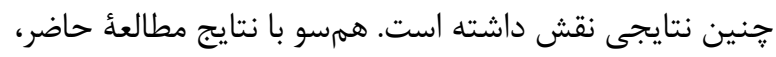

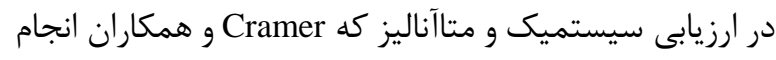

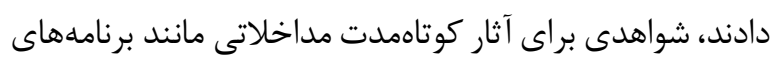

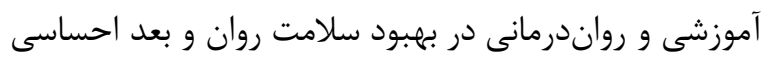

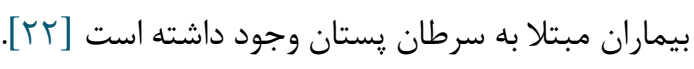

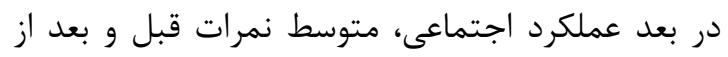

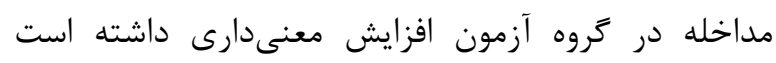

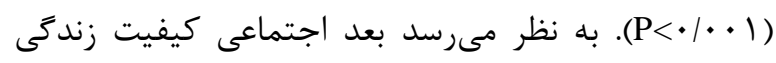

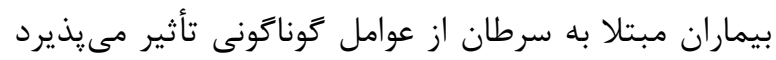

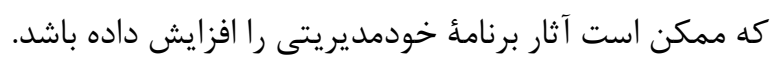
ارتباط خوب و مناسب اين بيماران با همسر، ساير اعضاى آناى

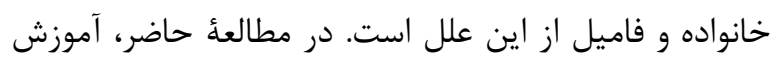

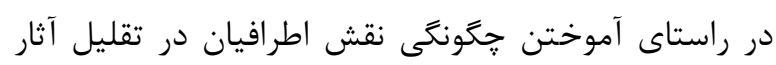

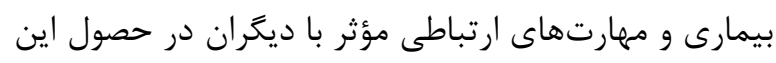

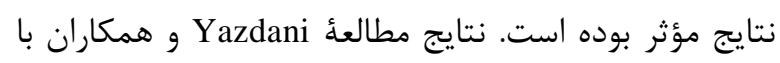

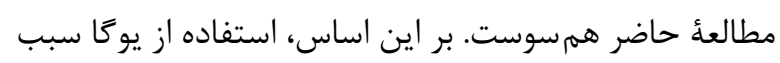

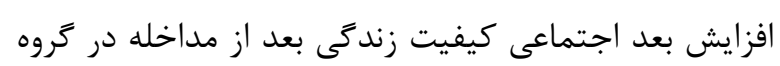

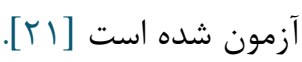
در بعد علائم خستگىى، متوسط نمرات قبل و بعد از مداخله

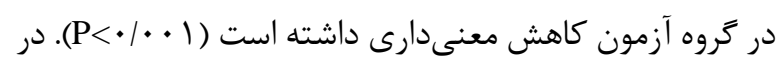

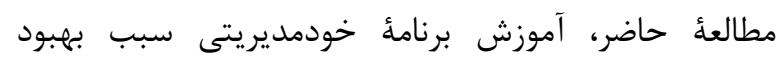

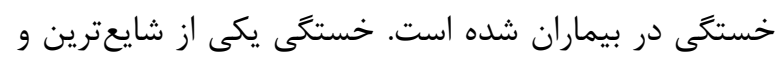

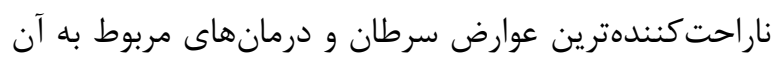

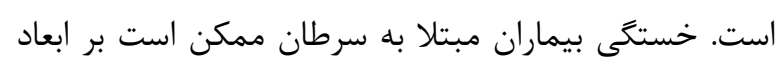

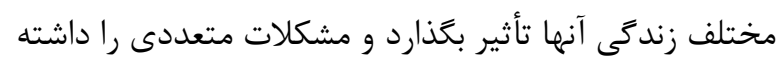

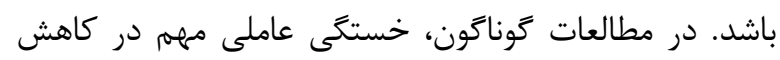

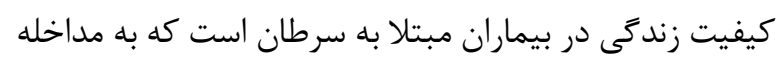

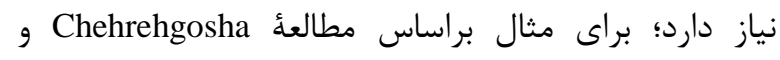

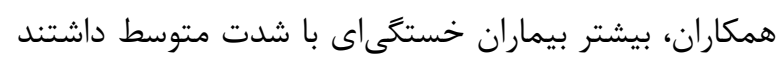

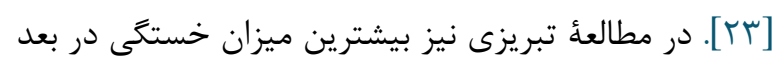

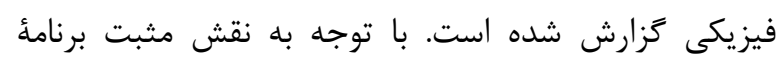

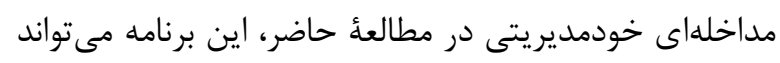

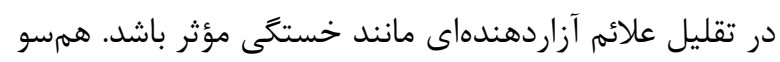

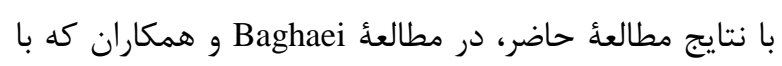

براساس نتايج مطالعهُ حاضر در همأ ابعاد كيفيت زندگى مانى

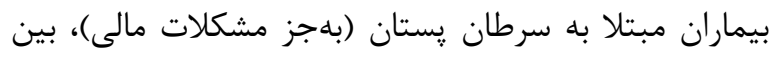

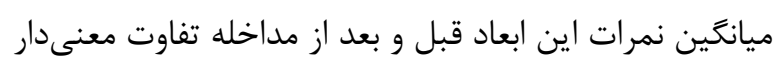

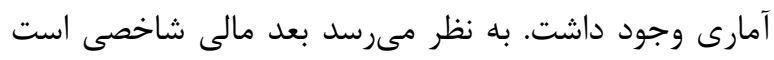

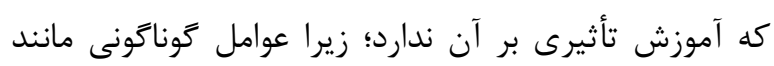

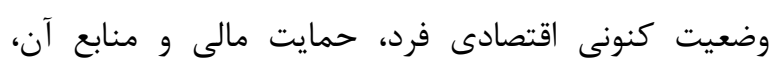

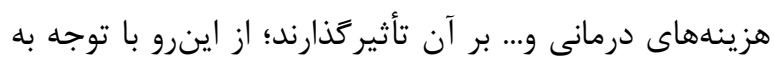

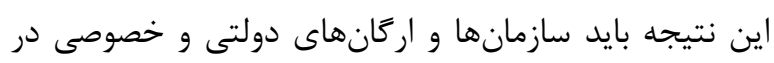

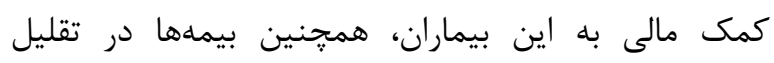
هزينهاى مختلف درمانى تلاش كنيند.

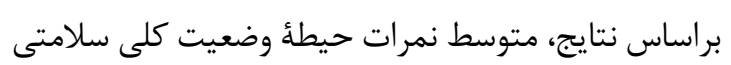

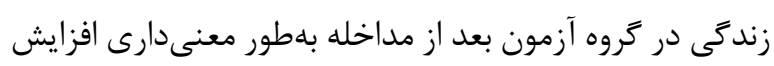

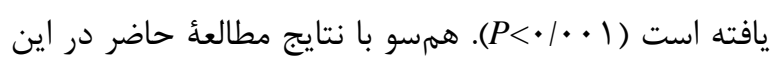
حيطه، Baghaei و همكاران بيان داشتند كه آموزش كاهش

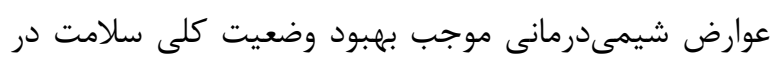

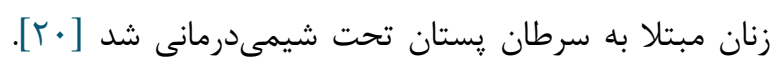

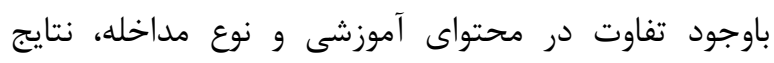
مشابهى در دو مطالعه حاصل شده است.

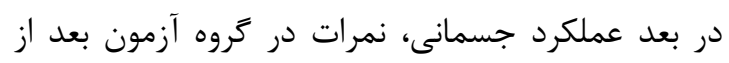

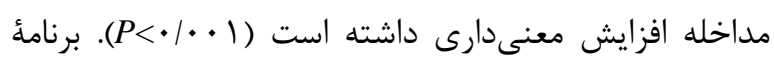

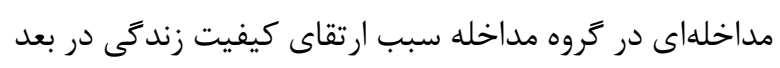

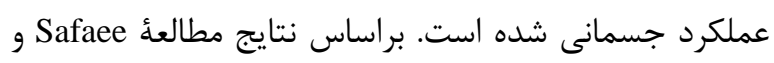

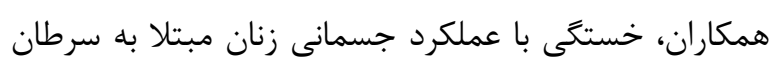

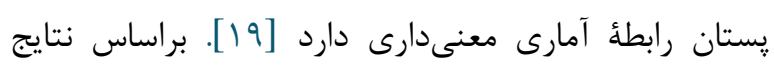

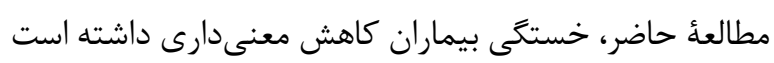

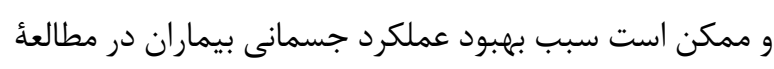

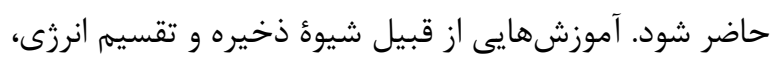

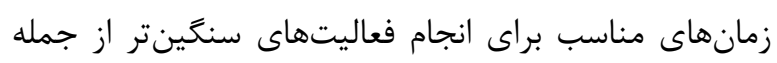
موارد يارى كننده در اين زمينه بود.

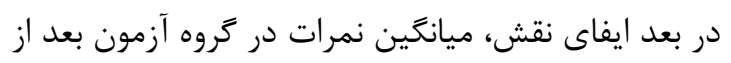

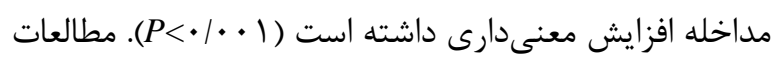

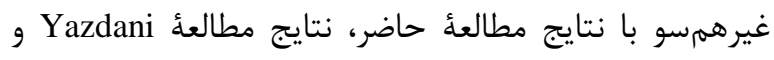

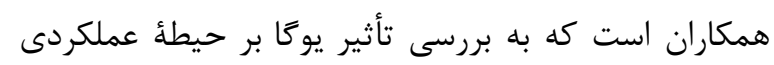

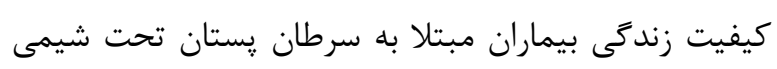

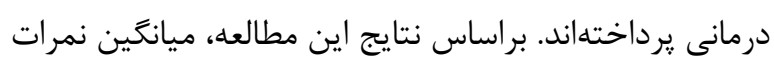

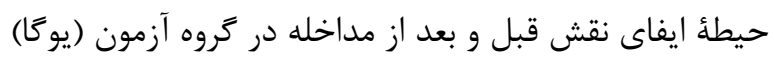

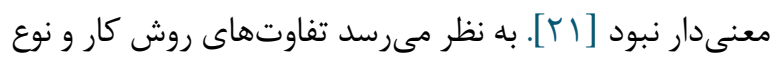
مداخله در دو مطالعه، علت تفاوت در نتايج باشد. 
بيماران تاثير كذارند. بسيارى از اين عوامل از كنترل يزوهشكر

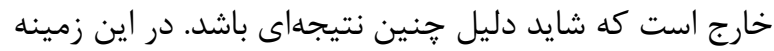
براساس نتايج مطالعه Kim حمايت اجتماعى از بيماران مبتلا به سرطان، تأثير ويزهاى بر كاهش بار اقتصادى ناشى از فرايند إنداند

بيمارى دارد [ع [ب].

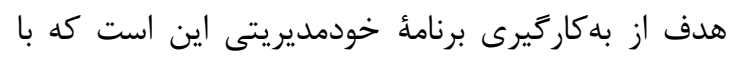

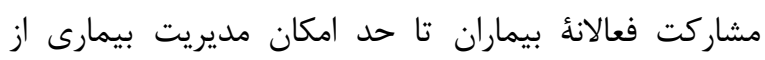

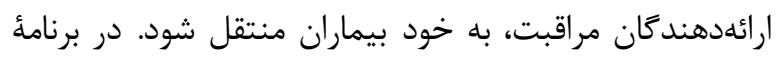
خودمديريتى، بيمار نقش محورى دارد و همأ فعاليتهاى

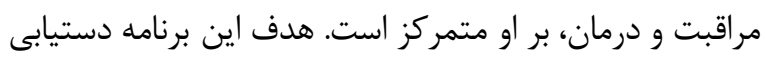

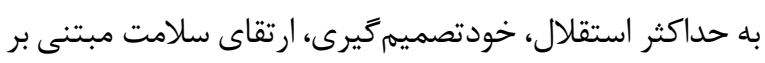

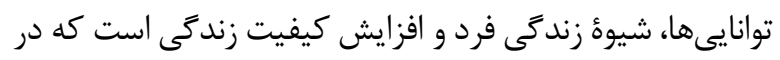

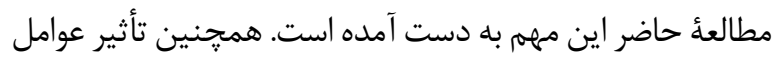

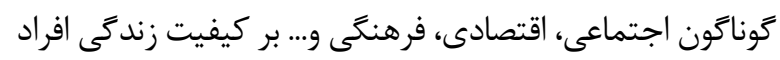

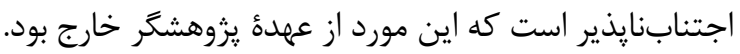

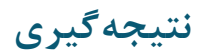

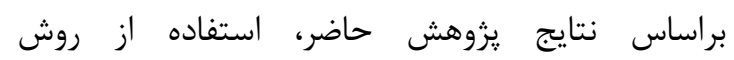

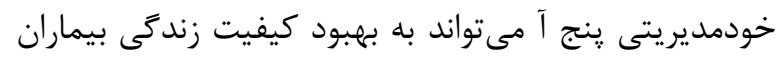

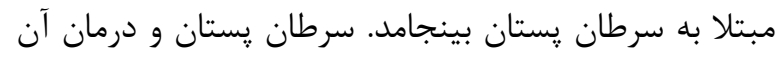

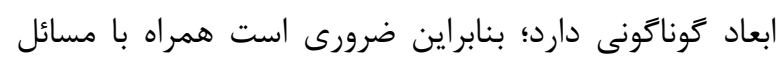

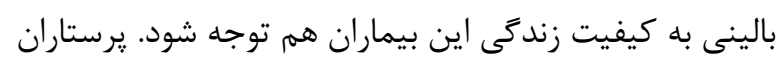

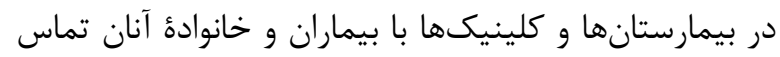

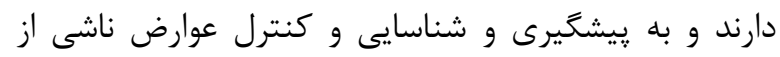

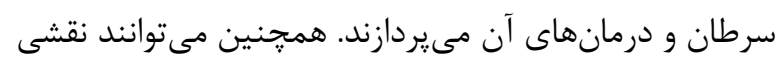

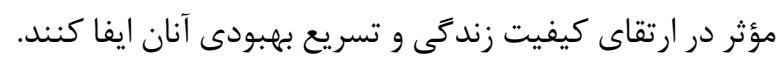

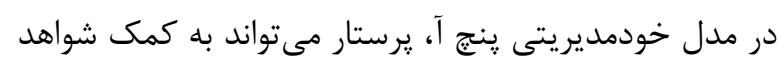

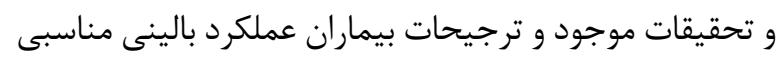

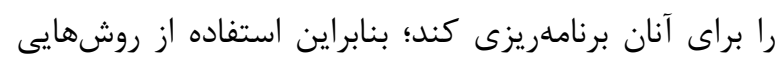

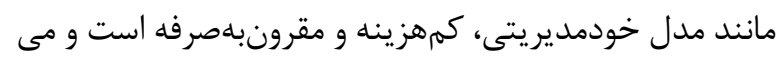

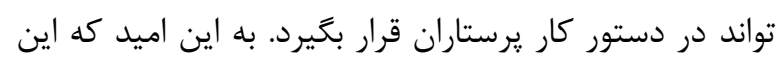

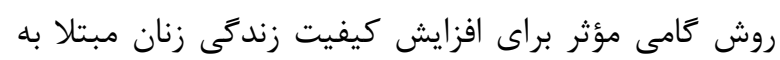
سرطان קِتان باشد.

\section{سياسگزارى}

نويسندًان از معاونت محترم تحقيقات و فناورى دانشكاه

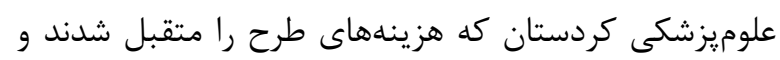

هدف تأثير آموزش كاهش عوارض شيمىدرانى بر ابعاد علامتى كيفيت زندگى بيماران مبتلا به سرطان صورت كرفتئ

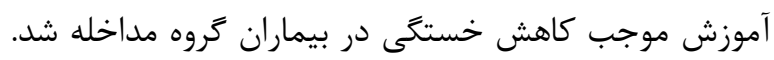

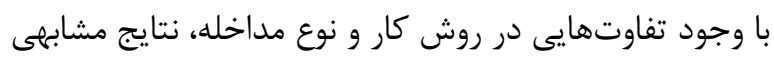
در مطالعهُ حاضر با مطالعئ فوق به دست آمده است. در بعد علائم تهوع و استفراغ، متوسط نمرات اين علائم

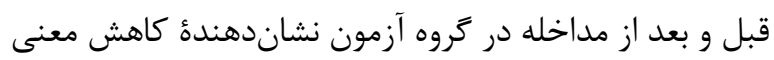

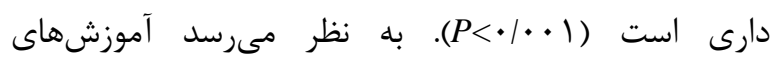
خودمديريتى در زمينهُ جگَونكى تغذئُ مناسب و حمايتهاى روحى طى آموزش، بر كاهش تهوع و استفراغ بيماران مؤثر

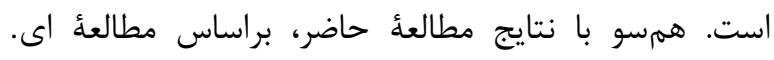

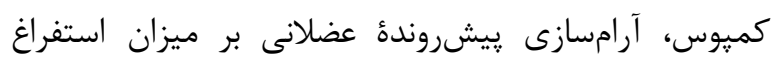
بيماران تروه آزمون مؤثر است.

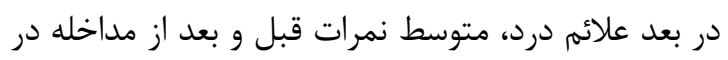

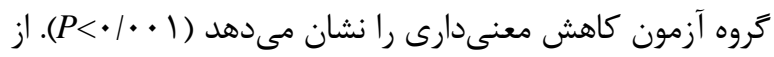

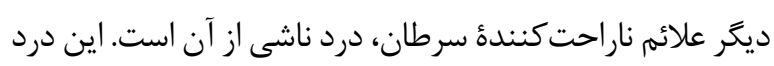

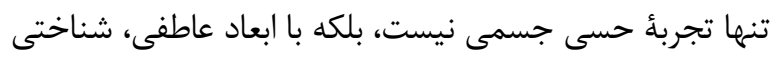

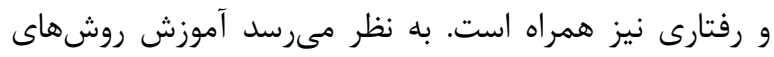

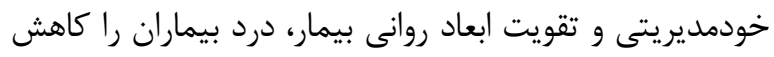

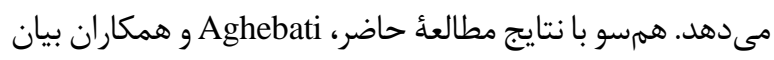

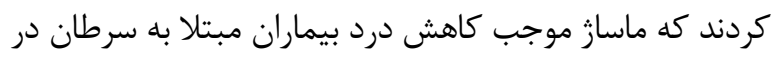

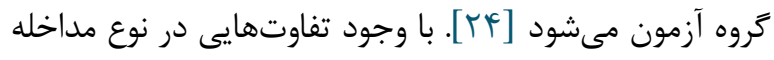

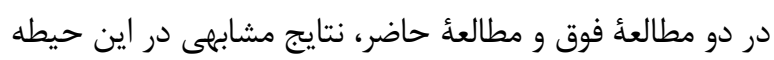

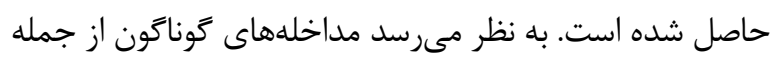

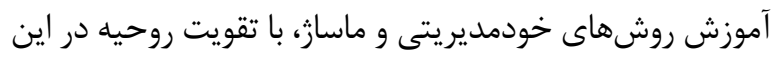
بيماران در كاهش درد مؤثر بوده است.

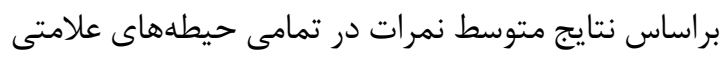

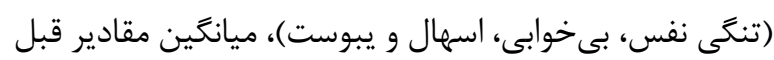

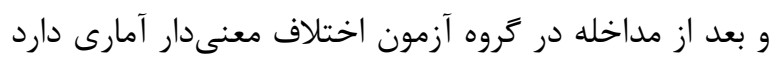

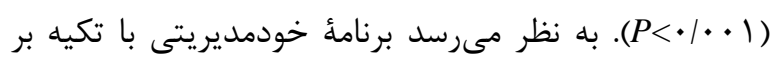

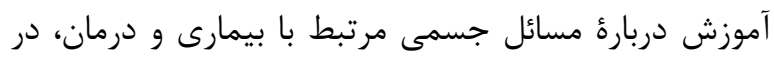

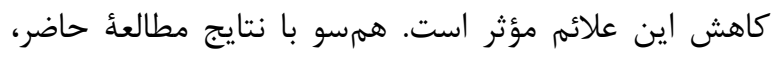

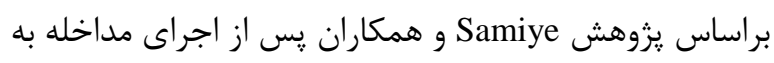

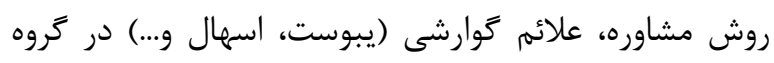

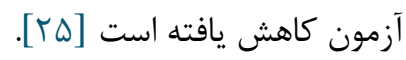

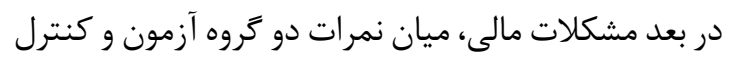

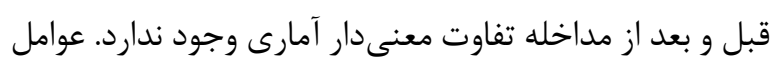
كوناگونى در شكل قيرى يا بهبود وضعيت اقتصادى و مالى معنى 


$$
\begin{aligned}
& \text { تعارض در منافع } \\
& \text { بين نويسند } \\
& \text { منابع مالى } \\
& \text { اين مقاله بخشى از رسالهُ دكترى و حامى مالى آن دانشگاه } \\
& \text { تربيتمدرس بود. }
\end{aligned}
$$

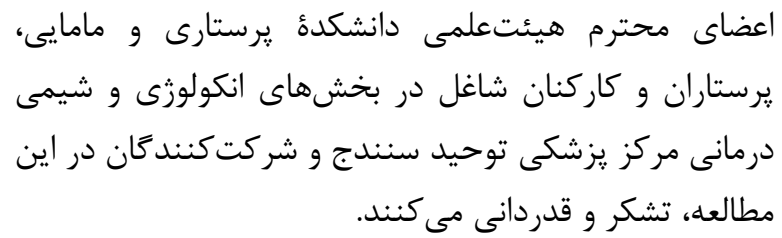

\section{References}

1. Mousavi SM, Gouya MM, Ramazani R, Davanlou M, Hajsadeghi N, Seddighi Z. Cancer incidence and mortality in Iran. Annals of oncology. 2008 Dec 10;20(3):556-63. [DOI:10.1093/annonc/mdn642] [PMID]

2. Siegel RL, Miller KD, Jemal A. Cancer statistics, 2016. CA: a cancer journal for clinicians. 2016 Jan;66(1):730. [DOI:10.3322/caac.21332] [PMID]

3. Hazrati M, Poor Keiani M, Abaszade A, Jaafari P. The effect of rehabilitation in quality of life in women after mastectomy. Armaghane danesh. 2008 Jan 15;12(4):89-99.

4. Asgarian F, Mirzaei M, Asgarian S, Jazayeri M. Epidemiology of breast cancer and the age distribution of patients over a period of ten years. Iranian Quarterly Journal of Breast Disease. 2016 Jul 15;9(1):31-6.

5. Hinkle JL, Cheever KH. Study Guide for Brunner \& Suddarth's Textbook of Medical-surgical Nursing. Lippincott Williams \& Wilkins; 2013 Nov 25.

6. Sona P, Fatemeh J, Arash K, Saeedeh A, Hengameh S. The impact of the implementation of the empowerment family-centered model on the performance scale of the lives quality of women with breast cancer undergoing chemotherapy. Research Journal of Pharmaceutical, Biological and Chemical Sciences. 2016;7(6):2095102.

7. Entezar-Mahdi R, Shamshiri A, Ramezani R, Eaatemad K. National breast cancer control program in IR IRAN, operational planning \& guideline for breast cancer screening with $\mathrm{CBE} \&$ Mammography. Ministry Health, Treatment \& Education Medicines Center for Disease Control \& Prevention Non-communicable Diseases Unit Cancer Office. 2011;127.

8. Matsuda A, Yamaoka K, Tango $\mathrm{T}$, Matsuda $\mathrm{T}$, Nishimoto H. Effectiveness of psychoeducational support on quality of life in early-stage breast cancer patients: a systematic review and meta-analysis of randomized controlled trials. Quality of Life Research. 2014 Feb 1;23(1):21-30. [DOI:10.1007/s11136-0130460-3] [PMID] [PMCID]

9. Kalani N, Mosalanejad L, Zabetian H, Abdolahifard S. The effect of group hope therapy integrated with mobile learning on hope and perceived stress levels in MS patients. Biosciences, Biotechnology Research Asia. 2015;12(3):1947-55. [DOI:10.13005/bbra/1861]
10. Phipps WJ, Monahan FD, Sands JK, Marek JF, Neighbors M. Medical-surgical nursing: Health and illness perspectives. St. Louis: Mosby; 2003.

11. Johnston S, Liddy C, Ives SM, Soto E. Literature review on chronic disease self-management. The Champlain local health integration network. 2008 Apr.

12. Ahmadi M, Poormansouri S. Effectiveness of selfmanagement educational program on fatigue in sickle cell patients. Journal of Clinical Nursing and Midwifery. 2015 May 15;4(2):29-42. [DOI:10.17795/jicdc-29521]

13. Glasgow RE, Davis CL, Funnell MM, Beck A. Implementing practical interventions to support chronic illness self-management. The Joint Commission Journal on Quality and Safety. 2003 Nov 1;29(11):56374. [DOI:10.1016/S1549-3741(03)29067-5]

14. Khani Jeihooni A, Kashfi SM, Hazavehei SM. Effects of the BASNEF model-based educational programs on blood Sugar control,(type 2 diabetes). Health Education \& Health Promotion. 2013 Mar 1;1(1):33-49.

15. Etemadi A, Sadjadi A, Semnani S, Nouraie SM, Khademi H, Bahadori MO. Cancer registry in Iran: a brief overview. Archives of Iranian medicine. 2008;11(5):577-80.

16. Bryant-Lukosius D, DiCenso A. A framework for the introduction and evaluation of advanced practice nursing roles. Journal of advanced nursing. 2004;48(5):530-40. https://doi.org/10.1111/j.13652648.2004.03234.x [DOI:10.1111/j.13652648.2004.03235.x]

17. Yazdani F, Babazade S. The effects of yoga on life quality of patients with breast cancer undergoing chemotherapy. Complementary Medicine Journal of faculty of Nursing \& Midwifery. 2014;3(4):624-38.

18. Nejat S, Montazeri A, Holakoei K, Mohammad K. standardization of WHOQOL-BREF: translation and psychometry of Iranian version. Journal of Health Science University. 2007;4(4):1-2.

19. Safaee A, Zeighami B, Tabatabaee HR, Moghimi Dehkordi B. Quality of life and related factors in breast cancer patients under chemotherapy. Iranian Journal of Epidemiology. $2008 \quad$ Feb 15;3(3):61-6. [DOI:10.4103/0019-509X.44066] [PMID]

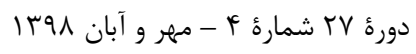

$$
\text { مجله مراقبت ڤبرستارى و مامايى ابنسينا }
$$


20. Baghaei R, Sheykhi N, Mohammadpour Y, SHarifi M. Evaluation of the effects of educational package on controlling the complications of chemotherapeutic agents on symptom scales of quality of life in patients with breast cancer undergoing chemotherapy. The Journal of Urmia Nursing and Midwifery Faculty. 2013;11(9):667-79.

21. Yazdani F, Babazade S. The effects of yoga on life quality of patients with breast cancer undergoing chemotherapy. Complementary Medicine Journal of faculty of Nursing \& Midwifery. 2014;3(4):624-38.

22. Cramer H, Lange S, Klose P, Paul A, Dobos G. Yoga for breast cancer patients and survivors: a systematic review and meta-analysis. BMC cancer. 2012 Dec;12(1):412. [DOI:10.1186/1471-2407-12-412] [PMID] [PMCID]

23. Chehrehgosha M, Dastourpour M, Sanagu A, Mohamadi A. Cancer-related Fatigue and its Relationship with Demographic and Clinical Characteristics. Jorjani Biomedicine Journal. 2013;1(2):24-31. (persian)

24. Aghebati N, Mohammadi E, Esmaeil ZP. The effect of relaxation on anxiety and stress of patients with cancer during hospitalization. Iran Journal of Nursing. 2010 Aug;23(65):15-22.

25. Samiye Siboni Fatemeh, Anousheh Monireh, Fatemeh A. The effect of family counseling on the quality of life of women with breast cancer undergoing chemotherapy. Journal of Nursing and Midwifery Faculty. 2010;20(71):289-98. (persian).

26. Kim J, Han JY, Shaw B, McTavish F, Gustafson D. The roles of social support and coping strategies in predicting breast cancer patients' emotional well-being: testing mediation and moderation models. Journal of health psychology. 2010 May;15(4):543-52. [DOI:10.1177/1359105309355338] [PMID] [PMCID] 